Lepr. Rev. (1969) 40, $111-116$

\title{
Treatment of Moderately Severe Erythema Nodosum Leprosum with Thalidomide - A Double-blind Controlled Trial*
}

\author{
J. M. H. PEARSON \\ Research Medical Officer, Sungei Buloh Leprosarium, Selangor, Malaysia \\ and National Institure for Medical Research, London, England \\ M. VEI)A(IRI \\ Medical ()fficer, Sungei Buloh Leprosarium, Selangor, Malaysic
}

\begin{abstract}
This carefully planned, controlled, double-blind trial of the value of thalidomide in the treatment of long-standing, moderately severe erythema nodosum leprosum showed that thalidomide was superior to a placebo, allowed for the concomitant reduction of other anti-ENL, drugs, and was clearly preferred by the patients themselves.
\end{abstract}

Erythema nodosum leprosum (ENL) remains a controversial topic, and its rational treatment is made difficult by the dearth of controlled trials of different managements. For instance, although most workers would advocate reducing or discontinuing antileprosy treatment when ENL develops, there is no study clearly demonstrating the value of this procedure. The place of corticosteroids in therapy is also controversial. There is general agreement that they are best avoided, but it has recently been shown (Karat et al., 1969) that patients with ENL (most of whom were not given steroids) developed more nerve damage than similar patients with no ENL; this might be prevented if steroids were used more freely than is commonly advised. Other drugs, such as chloroquin, antimonials, salicylates, and sedatives are widely used, but none has been adequately tested, and their efficacy requires further evaluation.

Thalidomide is a welcome exception, in that from the time of the accidental discovery (Sheskin, 1965a) of its effectiveness against ENL it has been subjected to a number of well planned and adequately controlled studies

* Received for publication 20 February, 1969.

Requests for reprints should be addressed to J. M. H. Pearson at the National Institute for Medical Research, Mill Hill, London, N.IV.7.
(Baccaredda-Boy et al., 1968; Convit et al., 1967; Sheskin, 1965b; Sheskin and Sagher, 1968; Waters, 1968). There is now no doubt that it is a highly effective drug which could probably replace steroids in the management of ENL, except in the case of women of child-bearing age. It has also been shown (Magora et al., 1968) to reverse acute nerve dysfunction occurring as part of this reaction. But its known teratogenic properties make close control essential, and its proper place in the management of FNL requires further accumulation of experience. At the Leprosy Research Unit in Sungei Buloh Leprosarium, thalidomide was first used in a doubleblind controlled trial carried out in 10 patients with severe ENL, who all required at least 15 to $20 \mathrm{mg}$ of prednisolone daily to control their reaction (Waters, 1968). It was found to be highly effective in such cases, and we therefore decided to undertake a further trial of the drug in patients with less severe ENI.

\section{ORGANIZATION OF THE TRIAL}

\section{Selection of patients}

All 12 patients admitted to the trial ( 11 males and one post-menopausal female (Case 4)) had been suffering from ENL for at least 10 months, and 11 of them for periods of between 1 and $: 3 \frac{1}{2}$ 
years. They had all received frequent courses of antimonials ("stibophen") and some required occasional courses of ACTH or corticosteroids in low dosage. All were suffering from lepromatous leprosy (clinically LL (Ridley and Jopling, 1966); there was biopsy confirmation in 11 cases-the twelfth was not subjected to biopsy). The diagnosis of ENL was made on clinical grounds.

\section{Anti-leprosy treatment}

In all cases anti-leprosy treatment was continued and neither drug nor dosage was altered during the study period or for at least 10 months preceding it. The drugs and dosages used are shown in Table 1.

TABLE I

Anti-leprosy treatment of trial patients

\begin{tabular}{llll}
\hline & Treatment & $\begin{array}{c}\text { No. of } \\
\text { patients }\end{array}$ & Case nos. \\
\hline I)DS & $50 \mathrm{mg}$ twice weekly & 6 & $1,2,3,7,8,9$ \\
& $100 \mathrm{mg}$ twice weekly & 2 & 5,6 \\
& $20(0 \mathrm{mg}$ twice weekly & 1 & 4 \\
& $300 \mathrm{mg}$ twice weekly & 1 & 10 \\
B 663 & $100 \mathrm{mg}$ daily & 2 & 11,12
\end{tabular}

\section{Anti-ENL treatment}

Thalidomide. Patients were allotted randomly to treatment with thalidomide, $100 \mathrm{mg} 3$ times daily (twice daily if weighing less than $35 \mathrm{~kg}$ $(77 \mathrm{lb})$, or with a placebo identical in appearance; after 6 weeks the treatment was reversed and continued for a further 6 weeks. Patient and nursing staff were unaware that a placebo was being used, and the research worker did not know which patient was receiving which tablet at any time.

Most of the patients were living in quarters in the hospital grounds; a few were in hospital. Patients in quarters attended the research ward daily, where their temperature was taken and a day's supply of tablets issued. It was not possible to watch each tablet being swallowed.

Other drugs. We have found that patients with ENL of this severity require treatment with effective reaction-suppressing drugs: it was therefore impossible to use a placebo without also allowing the use of additional anti-ENL treatment. It was decided to use only 3 other drugs; namely prednisolone, stibophen, and paracetamol. The first 2 were prescribed by the research worker according to our normal indications; paracetamol was supplied for the patients to take themselves as they wished. The principle of assessing response to treatment by the change in requirement of other anti-ENL drugs has been used successfully for steroids (Pettit, 1967; Waters, 1968) and we expected it would prove satisfactory for stibophen and paracetamol also.

\section{Assessments}

Patients were seen twice weekly by the research worker, who graded the severity of their ENL and prescribed treatment as indicated. Points were allotted for the severity of ENL, maximum temperature since previous assessment, requirement of other anti-ENL

TABLE 2

\section{Classification and scoring for each half-week period}

Parameter Definition $\quad \begin{gathered}\text { Score } \\ \text { (points) }\end{gathered}$

\section{Clinical}

(severity of ENL*)

$\begin{array}{ll}\text { No ENL } & 4 \\ \text { Mild ENL } & 3 \\ \text { Moderate ENL } & 2 \\ \text { Steroids required } & \\ \text { on one day } & 1 \\ \text { Steroids on more } & \\ \text { than one day } & 0\end{array}$

Fever

(maximum

temperature

recorded)

$\begin{array}{ll}<98.8^{\circ} \mathrm{F}\left(37.1^{\circ} \mathrm{C}\right) & 2 \\ 98.8 \text { to } 99.9^{\circ} \mathrm{F}\left(37.1-37.75^{\circ} \mathrm{C}\right) & 1 \\ >10\left(0^{\circ} \mathrm{F}\left(37.8^{\circ} \mathrm{C}\right)\right. & \text { 1) }\end{array}$

Stibophen requirement

()

l to $5 \mathrm{ml}$

$>5 \mathrm{ml}$

4 3 2 l )

Total WBC (when done)

\section{$<8000$ per ml} 8000 to 16,000 per $\mathrm{ml}$ $>16,000 \mathrm{ml}$

*Definitions of ENL_mild, few or moderate number of lesions, indolent or slightly active, causing no discomfort; moderate, lesions mild or moderately active, causing some discomfort. 
drugs, and total leukocyte count (performed every 2 weeks) as shown in Table 2 . It will be noted that the higher the score, the less severe is the ENL. The scoring was designed with the following aims:

(a) To give greatest weight to the clinical assessment, which is scored higher than the other parameters.

(b) To compensate for the effects of treatment. Thus a patient with active ENI, but no additional anti-ENL treatment might score ENL 2 + fever $1+$ treatment $2=5$. If treated, say with stibophen daily, his score could be expected to be ENL $3+$ fever $2+$ stibophen $0=\tilde{5}$.

At each assessment the number of paracetamol tablets taken by the patient was also recorded, as it was considered possible that this would give objective evidence of the patient's opinion of the severity of his reaction. It is clear that the method of scoring is highly subjective. Nevertheless we consider that this technique will give reliable results in relatively short trials when clinical assessments are all performed by the same workers.

\section{RESULTS}

Side-effects

There were few complaints of side-effects during the course of the trial. During the first week 3 patients complained of drowsiness and of these, 2 were receiving thalidomide and one the placebo. In all cases the drowsiness cleared after a few days and there were no complaints when the treatments were interchanged after 6 weeks. Constipation and dryness of the mouth were not observed. One patient developed mild dermatitis after 10 day's treatment with thalidomide; this subsided with local treatment, but recurred for a week when treatment was changed to the placebo. One patient complained of temporal headaches for a week during the placebo treatment. The one female patient (Case 4) developed intestinal obstruction of uncertain cause after 9 weeks and was withdrawn from the study. She was receiving treatment with thalidomide at the time. (Her average scores for the first 3 weeks of thalidomide have been inserted for weeks 10 to 12 ; this makes it possible to compare figures for drug and placebo treatment periods directly.)

Overall results

These are shown in Table 3.

TABLE 3

Total scores of all cases according to parameters during drug and placebo treatment

\begin{tabular}{|c|c|c|c|}
\hline \multirow[t]{2}{*}{ Parameter } & \multirow[t]{2}{*}{ Treatment } & \multicolumn{2}{|c|}{$\begin{array}{c}\text { Weekly scores } \\
\text { (total of all cases) }\end{array}$} \\
\hline & & Range & Average \\
\hline \multirow{2}{*}{$\begin{array}{l}\text { Clinical } \\
\text { condition }\end{array}$} & Drug & 59 to 70 & 65 \\
\hline & Placebo & 47 to 55 & 50 \\
\hline \multirow[t]{2}{*}{ Fever } & Drug & 4() to 47 & 43 \\
\hline & Placebo & 34 to 43 & 39 \\
\hline \multirow{2}{*}{$\begin{array}{l}\text { Stibophen } \\
\text { requirement }\end{array}$} & Drug & 40 to 46 & 42 \\
\hline & Placebo & 26 to 43 & 31 \\
\hline Total white & Drug & 20 to 26 & 22 \\
\hline blood count & Placebo & 14 to 22 & 18 \\
\hline \multirow{2}{*}{$\begin{array}{l}\text { Paracetamol } \\
\text { requirement } \\
\text { (no. of tablets) }\end{array}$} & Drug & 114 to 160 & 142 \\
\hline & Placebo & 212 to 282 & 246 \\
\hline
\end{tabular}

Clinical assessments. These show a clear difference between the 2 treatment periods. The lowest weeks' score during thalidomide treatment was greater than the highest during placebo treatment; i.e. the most severe ENI during thalidomide treatment was less than the mildest during placebo treatment.

Degree of fever. There was little difference between figures for the thalidomide and placebo periods; this might be expected as patients in the placebo group were receiving other effective anti-ENL drugs.

Stibophen treatment. Here the difference between the 2 groups was very clear cut, as during 5 out of the 6 weeks of placebo treatment patients needed more stibophen than the maximum required in any one week of thalidomide treatment.

White blood cell counts. There was little difference between the 2 sets of figures. As in the case of the degree of fever this probably reflects the effectiveness of the additional anti-ENI, treatment that was prescribed. 
Paracetamol requirements. There was a most striking difference between the 2 groups, in that the patients took almost twice as many tablets during treatment with the placebo. Since these tablets could be taken as and when the patients wished, these figures make it clear that the patients found thalidomide more effective than the placebo, even allowing for the extra stibophen injections they received during placebo treatment.

TABLE 4

Steroid requirements during the trial period

\begin{tabular}{ccc}
\hline Case no. & \multicolumn{2}{c}{$\begin{array}{c}\text { Total amount of prednisolone } \\
\text { prescribed (mg) }\end{array}$} \\
& $\begin{array}{c}\text { Thalidomide } \\
\text { treatment }\end{array}$ & $\begin{array}{c}\text { Placebo } \\
\text { treatment }\end{array}$ \\
\hline 3 & 0 & 35 \\
4 & 10 & 135 \\
8 & 400 & 630 \\
10 & 35 & 0 \\
12 & $50(0)$ & 345 \\
\hline
\end{tabular}

Steroid requirement. Five patients received steroids during the trial; Table 4 shows that 3 of the 5 required less prednisolone when treated with thalidomide. Of the other 2 , one (Case 10) received it for a few days only at the start of the thalidomide period; the other (Case 12) is discussed later.

The usual dosage of prednisolone was 5 to $10 \mathrm{mg}$ daily: larger doses than this were required by Case 8 for almost all the placebo period ( 15 to $20 \mathrm{mg}$ daily) and by Case 12 for the second half of the thalidomide period ( $12 \frac{1}{2}$ to $15 \mathrm{mg}$ daily).

Results for individual patients

A clear-cut benefit from thalidomide was shown in the over-all figures, but individual patients showed marked differences in their responses. Table 5 shows results for each of the patients arranged according to the severity of the ENI. (i.e. their scores during placebo treatment, mildest cases first). As might be expected the more severe cases show the most definite responses; this finding, however, reflects the system of scoring rather than the efficacy of the drug. The 2 exceptions (Cases 8 and 12) are considered in detail in the discussion below.
TABLE 5

Scores of individual patients during drug and placebo periods

\begin{tabular}{rcc} 
Case no. & $\begin{array}{c}\text { Total score during } \\
\text { placebo treatment }\end{array}$ & $\begin{array}{c}\text { Additional score during } \\
\text { thalidomide treatment }\end{array}$ \\
\hline 6 & 89 & +8 \\
11 & 82 & -1 \\
1 & 82 & +13 \\
5 & 81 & +12 \\
10 & 78 & +11 \\
9 & 60 & +31 \\
2 & 56 & +32 \\
4 & 56 & +25 \\
7 & 55 & +32 \\
12 & 50 & -7 \\
8 & 46 & +1 \\
3 & 39 & +23
\end{tabular}

\section{Rapidity of action of thalidomide}

The total scores of all patients for individual weeks are shown in Table 6 . It is clear that thalidomide was fully effective after only one week, and that it aifected the score even in the first week.

TABLE 6

Total weekly scores of all patients during drug and placebo treatment periods

\begin{tabular}{ccc}
\hline Week & $\begin{array}{c}\text { Total scores of } \\
\text { Placebo }\end{array}$ & $\begin{array}{c}\text { patients } \\
\text { Thalidomide }\end{array}$ \\
\hline 1 & 132 & 146 \\
2 & 138 & 160 \\
3 & 123 & 166 \\
4 & 139 & 158 \\
5 & 119 & 156 \\
6 & 123 & 168 \\
\hline
\end{tabular}

\section{DISCIJSSION}

\section{Method of study}

It is difficult to over-emphasize the importance of adequately controlled trials in the evaluation of drugs used in the management of ENL. There are obvious difficulties in performing drug trials in a condition which shows spontaneous fluctuations and has a variable but self-limiting course; even so it is surprising that so few satisfactory studies have been undertaken. The detailed technique and scoring of this trial could probably be improved, and will in 
any case require amendment according to the particular regimen undergoing trial. But it is considered that the methods of this study could readily be applied to testing any drug or other treatment of ENL, and would give reliable results even in a trial based on a relatively small number of patients over a short time.

\section{Selection of patients}

This is criticàl to any study of the treatment of ENL. Patients with very severe reaction will probably show no detectable response to a weakly active drug; and those with very mild ENL may not give a clear-cut response even to a highly effective drug. Patients with continuous severe reaction are suitable for trials of powerful anti-ENL agents: but cases such as the majority of patients in this study who had had fairly continuous ENL for some months but did not usually need steroids, are more suitable for the assessment of less effective drugs. Selection of cases may well prove to be the most important part of trials of drugs used to treat ENL.

Three of our patients apparently failed to respond to thalidomide. One of them (Case 12) had little visible reaction, but considerable bone pain and ulceration of the legs. Biopsy specimens were reported to show "reversal reaction" ("lepra reaction") rather than ENL. A second patient (Case 11) had what were, clinicially, definite ENL lesions, though mild and rather persistent: but biopsy examination showed evidence of a "reversal" reaction. The third patient (Case 8) had definite ENL, clinically and on biopsy; he needed less prednisolone when treated with thalidomide, and this response could be shown if the scoring system were modified. Cases 11 and 12 were included as being probably suitable and in order to make up numbers; but this was a mistake. It is strongly recommended that there should always be histological confirmation of the diagnosis of ENL in studies oi its treatment: and it is clear that small numbers of well selected patients will give a more clear-cut result than will a large group of less satisfactory cases.

\section{Clinical assessments}

These should always be carried out without previous results being available. They are not difficult to perform quickly and reproducibly once the worker has gained the habit of recording, each time he sees a patient, the number of ENL lesions (few, moderate, many) and their degree of "activity" (indolent, slightly active, active, ulcerating). It is unlikely that scoring could be standardized between different units; but in any single unit uniformity could easily be achieved.

\section{Anti-ENL treatment other than thalidomide}

The decision to prescribe prednisolone or stibophen was made on clinical assessment, and so these scores were determined on as subjective a basis as were the clinical assessments. But this does not mean that they are either irreproducible or unreliable. Any leprosy worker develops, in the course of time, his own indications for treatment. And providing he is not influenced by previous knowledge (by knowing, for instance, that an active and powerful anti-ENL drug is being taken), a short trial conducted by a single worker should give valid results.

\section{The patients' verdict}

The most surprising finding of this study was the clear preference of patients for thalidomide, shown by the amount of paracetamol they consumed. It is clear from this that thalidomide is effective to a greater degree than is revealed by the figures for the clinical and other assessments.

\section{SUMMARY}

Twelve patients with long-standing ENI but not usually requiring steroid treatment were subjected to a double-blind controlled trial of thalidomide in a dosage of $100 \mathrm{mg}: 3$ times daily. Their response was assessed clinically and by the reduction of their requirement of other antiENL treatment (stibophen and/or prednisolone). Thalidomide was shown to be superior to the placebo, and was also preferred by the patients, who consumed less paracetamol during the period of thalidomide treatment. 


\section{ACKNOWLEDGEMENTS}

We are most grateful to Dr. M. K. Bhojwani, and to the staff and patients of Sungei Buloh Leprosarium, without whose support and cooperation this work could not have been carried out. Our thanks are also due to Dr. D. S. Ridley for the biopsy reports, and to Dr. R. J. W. Rees and Dr. M. F. R. Waters for advice in the planning of this study. We are indebted to Dr. H. W. von Schrader Beielestein of Chemie Grünenthal GMBH, Stolbert/Rheinland, Germany, who generously provided thalidomide and the placebo for use in the study. One of us (M.V.) wishes to thank Tan Sri Dr. Mohd. Din b. Ahmad, Director of Medical Services, Malaysia, for permission to publish this paper. The Leprosy Research Unit, Sungei Buloh, is jointly administered by the British Medical Research Council and the Malaysian Ministry of Health.

\section{REFERENCES}

BACCAREDDA-BOy, A., BERTAMINo, R. and NUNZI, F. (1968). Comparative therapy in lepra reactions. Abstract 164, Ninth Int. Lepr. Congr., London 1968; Int. .J. Lepr. 36, 111 (in press).
CONvit, J., SOTO, J. M. and SHESKIN, $\therefore$ (1967). Thalidomide therapy in the lepra reaction. Int. .J. Lepr. $\mathbf{3 5}$, 446.

KARAT, A. B. A., FURness, M. A., KARAT, S. and RAO, P. S. S. (1969). Patterns of neurological involvement in relation to chronic and/or recurrent erythema nodosum leprosum. Lepr. Rev. 40, 49.

MAGORA, A., SHESKIN, J. and SAghel, F. (1968). Motor conduction velocity test of the ulnar nerve in leprosy reaction under thalidomide therapy. Abstract 134, Ninth Int. Lepr. Congr., London, 1968; Int. .J. Lepr. 36, (in press).

PetTit, J. H. S. (1967). The treatment of erythema nodosum leprosum with B 663. A controlled study. Int. .J. Lepr. 35, 11.

RIDLEY, D. S. and JOPLING, W. H. (1966). Classification of leprosy according to immunity: a five group system Int. .J. Lepr. 34, 255.

SHESKIN, J. (1965a). Thalidomide in the treatment of lepra reactions. J. clin. Pharmac. Therapeut. 6, $3(0) 3$.

SHESKIN, J. (1965b). Further observation with thalidomide in lepra reactions. Lepr. Rev. 36, 183.

SHESKIN, J. and SAGHED, F. (1968). The present status of thalidomide treatment in lepra reactions and leprosy. Abstract 161, Ninth Int. Lepr. Cong.. London, 1968; Int. .J. Lepr. 36, (in press).

WATERS, M. F. R. (1968). The management of erythema nodosum leprosum with particular reference to continued dapsone therapy. Abstract 163, Ninth Int. Lepr. Congr., London, 1968; Int. .J. Lepr. 36, (in press). 